\title{
The physical fitness of first-year osteopathic medical students
}

\author{
JOHN C. LICCIARDONE, DO \\ R. DONALD HAGAN, PhD
}

The authors studied the physical fitness of first-year students attending an osteopathic medical college between 1981 and 1986. Overall, $319(49.2 \%)$ of all students entering during this period participated in a comprehensive health and fitness assessment. The mean treadmill performance times for men and women were 20.4 minutes and 15.5 minutes, respectively, using a modified Balke protocol. Men and women were at the 72nd and 79th percentiles, respectively, for physical fitness. In multivariate regression models that adjusted for confounding variables, body fat percentage was a highly significant negative predictor of fitness in both men and women. Forced vital capacity was also a highly significant predictor in women. The results of the study suggest that the fitness of medical students can be improved by implementing health promotion measures that encourage regular physical activity and dietary modification. A greater emphasis on health promotion in the medical curriculum may help students to adopt more healthy behaviors and, in addition, encourage them to provide preventive medical counseling to their patients.

\footnotetext{
From the Department of Public Health and Preventive Medicine, Texas College of Osteopathic Medicine, Fort Worth, where Dr Licciardone is research director. Dr Hagan is currently at the Naval Health Research Center, San Diego, Ca.

Reprint requests to John C. Licciardone, DO, Department of Public Health and Preventive Medicine, Texas College of Osteopathic Medicine, 3500 Camp Bowie Blvd, Fort Worth, TX 76107-2690.
}

(Key words: Medical students, physical fitness, health promotion, maximal exercise test, osteopathic medicine)

First-year medical students are aware of the importance of promoting good health habits to patients. ${ }^{1}$ However, it is generally believed that medical students are forced to curtail their own health promotion behaviors because of the constraints imposed by the rigorous curriculum. ${ }^{2-6}$ A survey of first-year medical students demonstrated that they rated certain elements of exercise, nutrition, and stress reduction to be significantly more important than did medical college faculty members. ${ }^{1}$ Although health promotion programs for medical students have not received high priority in the past, there now appears to be growing interest. Health promotion activities for medical students may range from those concerned primarily with regular exercise to those that address the issue of the impaired physician. ${ }^{7}$

Relatively little has been published about the physical fitness of medical students. A South African study ${ }^{2}$ conducted in 1972 found that both male and female medical students had significantly lower levels of endurance than did control subjects. However, the study was limited in size and used male army recruits and female physical education students as control subjects. ${ }^{2}$ A 1987 Canadian study of the fitness of male medical students placed them in the 60 th percentile for Canadian men, whereas female medical students were in the 95 th percentile of women in the general population. ${ }^{6}$ 
The study reported here was undertaken to: (1) measure the physical fitness of first-year osteopathic medical students, (2) identify health behavioral and physiologic factors that are strongly predictive of fitness, and (3) identify health promotion activities of importance for medical students.

\section{Methods \\ Study population}

Between 1981 and 1986, all first-year students at the Texas College of Osteopathic Medicine (TCOM) were invited to participate in a physical fitness study. After completion of an informed consent form and a medical history questionnaire, each student underwent a comprehensive health and fitness assessment. This assessment included a medical examination by a physician, determination of body composition by measurement of skinfolds, a blood lipoprotein profile, spirometry, and a maximal treadmill exercise test.

\section{Body composition}

Body height and weight were measured on a standard medical scale with the student in shorts, and the body mass index $\left(\mathrm{kg} / \mathrm{m}^{2}\right)$ was computed. Body density was determined from measures of seven skinfold sites (chest, midaxilla, triceps, subscapula, abdomen, suprailiac, and thigh) by use of the equations of Jackson and Pollock, ${ }^{8,9}$ and body fat percentage was computed with the Siri equation..$^{10} \mathrm{Fat}$ and lean body weight were then computed using the total body weight and body fat percentage.

\section{Blood lipoprotein profile}

A fasting (12 to 14 hours) blood sample was obtained from an antecubital vein, with the student in the seated position, and analyzed for total cholesterol (TC), high-density lipoprotein cholesterol (HDL-C), and triglycerides. The ratio of TC to HDL$\mathrm{C}$ was then computed.

\section{Spirometry}

Measures of forced vital capacity (FVC) and forced expiratory volume in 1 second $\left(\mathrm{FEV}_{1}\right)$ were made with a rolling seal Ohio Medical spirometer. The ratio of $\mathrm{FEV}_{1}$ to $\mathrm{FVC}$ was then computed and reported as a percentage.

\section{Physiologic measures and physical fitness}

Resting heart rate was obtained from a 12-lead electrocardiogram after 15 minutes of rest in the supine position. Systolic and diastolic blood pressure readings were obtained by brachial auscultation. Physical fitness was determined by a maximal treadmill exercise test according to a modified Balke and Ware protocol. ${ }^{11}$ The speed of the treadmill was held constant at $3.4 \mathrm{mph}$. The grade was set at $0 \%$ for the first minute, raised to $2 \%$ at the end of the first minute, and then increased $1 \%$ every minute until the 25th minute, at which point the speed was increased in increments of $0.2 \mathrm{mph}$.

A 3-channel electrocardiogram and a display screen were used to monitor each student during the exercise test and for 8 minutes after the test. The exercise test was conducted according to the guidelines recommended by the American College of Sports Medicine. ${ }^{12}$ Heart rate and blood pressure were measured at regular intervals during the exercise test.

\section{Statistical analyses}

Cross tabulations and chi-square analyses were used to assess the levels of participation in the study by year of matriculation and gender. The mean treadmill performance times for male and female medical students were then compared with those of age- and gender-specific reference populations ${ }^{13}$ to determine their levels of physical fitness. Analysis of variance for unequal group sizes was used to determine if short-term trends were present in any of 20 physical fitness predictor variables according to year of matriculation or gender. All hypotheses were tested at the .05 level of statistical significance.

A series of gender-specific univariate regression models was used to determine the relative importance of each of the 20 variables in predicting treadmill performance time. Stepwise multivariate regression was then used to adjust for potential confounding, and gender-specific models for predicting treadmill performance time were developed. All computations were performed with the SAS computer software package. ${ }^{14}$

\section{Results}

\section{Participants}

The distribution of participating students by year of matriculation and gender is presented in Table 1. Overall, $319(49.2 \%)$ of 648 eligible students participated in health and fitness assessments. There was a significant trend in participation according to year of matriculation $\left(\chi^{2}=17.3, P=.004\right)$; the percentage of participants increased from 1981 through 1983 and generally declined thereafter. Almost 
Table 1

Distribution of Osteopathic Medical Students Who Participated in Health and Fitness Assessments, by Year of Matriculation and Gender

\begin{tabular}{|c|c|c|c|c|c|c|c|c|c|}
\hline \multirow[b]{3}{*}{ Year } & \multicolumn{3}{|c|}{ Men } & \multicolumn{3}{|c|}{ Women } & \multicolumn{3}{|c|}{ Total } \\
\hline & \multirow{2}{*}{$\begin{array}{c}\text { No. } \\
\text { matricu- } \\
\text { lating }\end{array}$} & \multicolumn{2}{|c|}{ Participants } & \multirow{2}{*}{$\begin{array}{l}\text { No. } \\
\text { matricu- } \\
\text { lating }\end{array}$} & \multicolumn{2}{|c|}{ Participants } & \multirow{2}{*}{$\begin{array}{c}\text { No. } \\
\text { matricu- } \\
\text { lating }\end{array}$} & \multicolumn{2}{|c|}{ Participants } \\
\hline & & No. & $\%$ & & No. & $\%$ & & No. & $\%$ \\
\hline 1981 & 79 & 33 & 41.8 & 29 & 12 & 41.4 & 108 & 45 & 41.7 \\
\hline 1982 & 70 & 43 & 61.4 & 34 & 17 & 50.0 & 104 & 60 & 57.7 \\
\hline 1983 & 69 & 45 & 65.2 & 38 & 22 & 57.9 & 107 & 67 & 62.6 \\
\hline 1984 & 70 & 29 & 41.4 & 42 & 23 & 54.8 & 112 & 52 & 46.4 \\
\hline 1985 & 88 & 37 & 42.0 & 26 & 17 & 65.4 & 114 & 54 & 47.4 \\
\hline 1986 & 75 & 32 & 42.7 & 28 & 9 & 32.1 & 103 & 41 & 39.8 \\
\hline Total & 451 & 219 & 48.6 & 197 & 100 & 50.8 & 648 & 319 & 49.2 \\
\hline
\end{tabular}

Table 2

Characteristics of Osteopathic Medical Students Participating in Health and Fitness Assessments

\begin{tabular}{|c|c|c|c|c|}
\hline \multirow[b]{2}{*}{ Variable* } & \multicolumn{2}{|c|}{$\operatorname{Men}(n=219)$} & \multicolumn{2}{|c|}{ Women $(n=100)$} \\
\hline & Mean & SD & Mean & SD \\
\hline Age, yr $\dagger$ & 27.1 & 4.1 & 28.0 & 5.4 \\
\hline \multicolumn{5}{|l|}{ Body composition } \\
\hline $\begin{array}{l}\text { Height, } \mathrm{cm} \\
\text { Weight, } \mathrm{kg}\end{array}$ & 178.4 & 7.1 & $\begin{array}{r}165.1 \\
59.6\end{array}$ & $\begin{array}{r}7.3 \\
10.4\end{array}$ \\
\hline $\begin{array}{l}\text { Weight, } \mathrm{kg} \\
\text { Body mass index, } \mathrm{kg} / \mathrm{m}^{2}\end{array}$ & $\begin{array}{l}76.8 \\
24.1\end{array}$ & $\begin{array}{r}11.6 \\
3.4\end{array}$ & $\begin{array}{l}59.6 \\
21.9\end{array}$ & $\begin{array}{r}10.4 \\
3.7\end{array}$ \\
\hline $\begin{array}{l}\text { Body mass index, } \mathrm{kg} / \mathrm{m}^{2} \\
\text { Body fat, \% }\end{array}$ & $\begin{array}{l}24.1 \\
15.4\end{array}$ & $\begin{array}{l}0.4 \\
6.2\end{array}$ & 23.5 & 6.3 \\
\hline Lean body weight, $\mathrm{kg}$ & 64.5 & 7.4 & 45.1 & 5.3 \\
\hline Fat body weight, $\mathrm{kg}$ & 12.3 & 6.4 & 14.5 & 6.6 \\
\hline \multicolumn{5}{|l|}{ Blood lipoproteins } \\
\hline $\begin{array}{l}\text { Total cholesterol, } \mathrm{mg} / \mathrm{dL}^{\dagger} \\
\text { Total cholesterol to }\end{array}$ & 186.0 & 33.8 & 183.8 & 31.7 \\
\hline \multicolumn{5}{|l|}{ Total cholesterol to } \\
\hline cholesterol ratio & 4.1 & 1.5 & 3.2 & 0.9 \\
\hline $\begin{array}{l}\text { Triglyceride level, mg/dL } \\
\text { Pulmonary function }\end{array}$ & 103.8 & 60.2 & 85.0 & 57.2 \\
\hline $\begin{array}{l}\text { Pulmonary function } \\
\text { Forced vital capacity (FVC), L }\end{array}$ & & & & \\
\hline $\begin{array}{l}\text { Forced vital capacity (FVC), L } \\
\text { Forced expiratory volume }\end{array}$ & 5.5 & 0.8 & 3.9 & 0.6 \\
\hline in 1 second $\left(\mathrm{FEV}_{1}\right), \mathrm{L}$ & 4.5 & 0.6 & 3.3 & 0.5 \\
\hline FVC to $\mathrm{FEV}_{1}$ ratio $(\times 100 \%)$ & 81.4 & 7.7 & 86.3 & 6.9 \\
\hline Never smoked (proportion) & \multicolumn{2}{|c|}{0.780} & \multicolumn{2}{|c|}{0.755} \\
\hline Cardiorespiratory status & & & 70.0 & 12.0 \\
\hline $\begin{array}{l}\text { Resting heart rate, beats per minute } \\
\text { Resting systolic blood }\end{array}$ & 67.4 & 11.2 & 70.0 & 12.0 \\
\hline pressure, $\mathrm{mm} \mathrm{Hg}$ & 122.4 & 12.6 & 111.4 & 12.1 \\
\hline $\begin{array}{l}\text { Resting diastolic blood } \\
\text { pressure, } \mathrm{mm} \mathrm{Hg}\end{array}$ & 76.7 & 9.0 & 71.7 & 9.6 \\
\hline $\begin{array}{l}\text { Maximum treadmill heart rate, } \\
\text { beats per minute }\end{array}$ & 192.0 & 9.9 & 187.4 & 11.1 \\
\hline $\begin{array}{l}\text { Maximum treadmill systolic } \\
\text { blood pressure, } \mathrm{mm} \mathrm{Hg}\end{array}$ & 188.5 & 20.5 & 160.2 & 21.2 \\
\hline $\begin{array}{l}\text { Maximum treadmill diastolic } \\
\text { blood pressure, } \mathrm{mm} \mathrm{Hg}\end{array}$ & 56.5 & 21.2 & 59.6 & 13.8 \\
\hline Treadmill performance time, minutes & 20.4 & 4.4 & 15.5 & 4.3 \\
\hline
\end{tabular}


Table 3

Summary of Univariate Regression Analyses for Physical Fitness

\begin{tabular}{|c|c|c|c|c|}
\hline \multirow[b]{2}{*}{ Variable* } & \multicolumn{2}{|c|}{$\operatorname{Men}(n=219)$} & \multicolumn{2}{|c|}{ Women $(n=100)$} \\
\hline & $\mathbf{S C}^{*}$ & $P \dagger$ & SC & $P \dagger$ \\
\hline $\begin{array}{l}\text { Age, yr } \\
\text { Body composition }\end{array}$ & -2.89 & .004 & -2.19 & .03 \\
\hline Height, $\mathrm{cm}$ & 1.79 & .08 & 2.35 & .02 \\
\hline Weight, kg & -4.78 & .0001 & -1.65 & .10 \\
\hline Body mass index, $\mathrm{kg} / \mathrm{m}^{2}$ & -6.39 & .0001 & -3.33 & .001 \\
\hline Body fat, $\%$ & -10.32 & .0001 & -4.54 & .0001 \\
\hline Lean body weight, $\mathrm{kg}$ & -0.22 & .083 & 1.07 & .29 \\
\hline $\begin{array}{l}\text { Fat body weight, kg } \\
\text { Blood lipoproteins }\end{array}$ & -9.29 & .0001 & 3.68 & .0004 \\
\hline Total cholesterol, mg/dL & -3.03 & .003 & -0.33 & .74 \\
\hline $\begin{array}{l}\text { Total cholesterol to } \\
\text { high-density-lipoprotein } \\
\text { cholesterol ratio }\end{array}$ & -3.20 & .002 & -2.37 & 02 \\
\hline $\begin{array}{l}\text { Triglyceride level, mg/dL } \\
\text { Pulmonary function }\end{array}$ & -5.08 & .0001 & -1.46 & .15 \\
\hline $\begin{array}{l}\text { Forced vital capacity (FVC), L } \\
\text { Forced expiratory volume }\end{array}$ & 3.01 & .003 & 4.27 & .0001 \\
\hline in 1 second $\left(\mathrm{FEV}_{1}\right), \mathrm{L}$ & 2.02 & .04 & 3.72 & .0003 \\
\hline $\mathrm{FEV}_{1}$ to $\mathrm{FVC}$ ratio $(\times 100 \%)$ & -2.31 & .02 & -0.66 & .51 \\
\hline $\begin{array}{l}\text { Never smoked (proportion) } \\
\text { Cardiorespiratory status }\end{array}$ & 1.75 & .08 & 0.70 & .49 \\
\hline $\begin{array}{l}\text { Resting heart rate, beats per minute } \\
\text { Resting systolic blood }\end{array}$ & -4.37 & .0001 & -2.40 & .02 \\
\hline $\begin{array}{l}\text { pressure, } \mathrm{mm} \mathrm{Hg} \\
\text { Resting diastolic blood }\end{array}$ & -1.22 & .22 & -1.21 & .23 \\
\hline $\begin{array}{l}\text { pressure, } \mathrm{mm} \mathrm{Hg} \\
\text { Maximum treadmill heart rate, }\end{array}$ & -1.83 & .07 & -2.76 & .007 \\
\hline $\begin{array}{l}\text { beats per minute } \\
\text { Maximum treadmill systolic }\end{array}$ & 3.07 & .002 & 3.27 & .002 \\
\hline $\begin{array}{l}\text { blood pressure, } \mathrm{mm} \mathrm{Hg} \\
\text { Maximum treadmill diastolic }\end{array}$ & 0.24 & .81 & 1.18 & .24 \\
\hline blood pressure, $\mathrm{mm} \mathrm{Hg}$ & -2.90 & .004 & -3.91 & .0002 \\
\hline
\end{tabular}

equal percentages of men $(48.6 \%)$ and women $(50.8 \%)$ participated $\left(\chi^{2}=0.27, P=.61\right)$.

\section{Characteristics of the participants}

Because there were no significant temporal trends observed for any of the 20 physical fitness predictor variables, the data were not further analyzed by year of matriculation. The characteristics of the participating medical students according to gender are presented in Table 2. Significant gender differences were observed for all variables except age at matriculation and the level of total cholesterol. The mean treadmill performance times for men and women were 20.4 minutes and $15.5 \mathrm{~min}$ utes, respectively. When compared with age- and gender-specific reference populations, male and female medical students were at the 72nd and 79th percentiles, respectively, for physical fitness.

\section{Regression models}

The gender-specific univariate regression analyses are summarized in Table 3. A total of 17 predictor variables for treadmill performance time were either significant or demonstrated a trend toward significance $(P<.10)$ in the univariate analyses for men; only lean body weight, resting systolic blood pressure, and maximum treadmill systolic blood pressure were poor predictors of treadmill performance time. In general, similar results were observed 
for women, although fewer variables demonstrated statistical significance.

The gender-specific multivariate regression analyses are summarized in Table 4. Following adjustment for confounding, only five predictor variables continued to demonstrate statistical significance in men. Body fat percentage $(P<.0001)$, resting heart rate $(P=.002)$, the ratio of $\mathrm{FEV}_{1}$ to $\mathrm{FVC}(P=.01)$, and the ratio of TC to HDL-C) $(P=.02)$ were inversely related to treadmill performance time, whereas maximum treadmill heart rate $(P=.003)$ was directly related to treadmill performance time. These five variables accounted for $48 \%$ of the total variance in predicting treadmill performance time compared with $53 \%$ for a regression model that included all 20 predictor variables.

In women, body fat percentage $(P=.0004)$ and resting heart rate $(P=.01)$ were also significant negative predictors of treadmill performance time in the multivariate analyses. However, the ratio of $\mathrm{FEV}_{1}$ to $\mathrm{FVC}$, the ratio of TC to HDL-C, and maximum treadmill heart rate were not significant predictors. Instead, FVC was a highly significant predictor of treadmill performance time $(P<.0001)$ and resting systolic blood pressure was inversely related to treadmill performance time $(P=.04)$. These four variables also accounted for $48 \%$ of the total variance in predicting treadmill performance time compared with $59 \%$ for a regression model that included all 20 predictor variables.

\section{Discussion}

\section{Physical fitness of osteopathic medical students}

The results of this study suggest that firstyear osteopathic medical students have higher physical fitness levels than does the general population. In addition, there was no major dif-
Table 4
egression Analyses for Physical Fitness*

Summary of Multivariate Regression Analyses for Physical Fitness*

$\frac{\text { Men }(n=219)}{\text { SC }^{\dagger} \quad P} \frac{\text { Women }(n=100)}{\text { SC }^{\dagger} \quad P}$

$\begin{array}{llll}-9.55 & .0001 & -3.74 \quad .0004\end{array}$

$-2.37 \quad .02$

.

Pulmonary function

orced vital capacity

$\mathrm{FEV}_{1} \ddagger$ to $\mathrm{FVC}$ ratio $-2.65$

4.53

.0001

01

...

...

Cardiorespiratory status

Resting heart rate, beats

Resting systolic blood

pressure, $\mathrm{mm} \mathrm{Hg}$

$-3.08$

.002

$-2.67$

.01

$-2.09$

.04

\section{$3.00 \quad .003$}

*Only statistically significant variables $(P \leqslant .05)$ are reported for the multivariate models: $P \leqslant .0001$ is reported as $P=.0001 ; R^{2}=.48$ for the multivariate model including the five significant predictor variables reported in men and $R^{2}=.48$ for the multivariate model ncluding only four significant predictor variables reported in women

$\mathrm{SC}=$ standardized coefficient.

$\mathrm{FEV}_{1}$ = forced expiratory volume in 1 second

ference in the fitness levels of male and female students. These findings must be interpreted with caution, however, because only half of the eligible students participated in the study.

Data are unavailable to assess the degree to which the participating students were representative of all first-year students with respect to the health behavioral and physiologic variables measured in the study. Further, there was a significant temporal trend in participation, as students were more likely to have participated in the earlier years of the study. There is no clear explanation for this trend. However, it is unlikely to have had a major effect on the results because there were no significant temporal trends observed in any of the 20 physical fitness predictor variables.

Although many variables were significantly related to treadmill performance time in the univariate analyses, only body fat percentage was identified as being strongly predictive of fitness in both men and women in the multivariate analyses that adjusted for confound- 
ing variables. The cross-sectional nature of the study does not allow us to determine if a temporal sequence exists between low body fat percentage and physical fitness. Nevertheless, in light of this strong relationship, every effort should be made to encourage reductions in the body fat percentages of medical students by means of regular physical activity and dietary modification. The mean body fat percentage of men $(15.4 \%)$ was slightly below the average gender-specific range $(16 \%$ to $19 \%)$, whereas that of women $(23.5 \%)$ was above the corresponding range $(19 \%$ to $22 \%))^{13}$

Another finding was the significance of the ratio of TC to HDL-C in predicting fitness in the male, but not the female, students. This fact probably reflects the inherently greater HDL-C levels and more homogeneous ratio of TC to HDL-C in the adult premenopausal woman. ${ }^{15}$ In women, FVC was a highly significant predictor of fitness, whereas in men the ratio of $\mathrm{FEV}_{1}$ to $\mathrm{FVC}$ was a negative predictor of fitness. Both of these relationships indicate the importance of FVC in predicting physical fitness.

In addition, resting heart rate, resting systolic blood pressure, and maximum treadmill heart rate were significantly related to fitness in one or both genders. It is interesting to note that a few simple measures of body composition, blood lipoprotein levels, pulmonary function, and physiologic factors can account for almost one-half of the variance in predicting physical fitness $\left(R^{2}=.48\right.$ for the multivariate regression models presented in Table 4).

\section{Health of osteopathic medical students}

These findings have important implications for the health of osteopathic medical students. Current programs of medical education involve many hours of lectures, laboratory work, and study outside of the classroom. Further, the relatively short period of formal education, the large amount of material to be learned, and the long hours of study force the medical student to forego sleep and normal routines of food consumption and physical activity, and to become more sedentary. ${ }^{5,16}$ These rigors may adversely affect the student's ability to make proper medical judgments as well as place the student at an increased risk of fatigue and stress.

It has been shown that regular exercise has an important impact on the psychological status of the individual. ${ }^{17}$ Although the underlying mechanisms are unknown, experimental studies have consistently shown that vigorous exercise reduces anxiety and depression with an effectiveness equal to other therapeutic modalities such as simple rest, relaxation, or meditation. Competitive athletes tend to be emotionally stable, have low levels of anxiety, and present a mood profile indicative of effective stress management, with generalized feelings of achievement, patience, and self-esteem. ${ }^{17}$

The findings from a large cross-sectional study of adult men and women indicate that individuals who exercise and have a high level of physical fitness tend to have a low level of mental tension and fewer somatic complaints. ${ }^{18}$ Further, it has been postulated that illness and mortality are closely related to the environment, group processes, and individual behavior. ${ }^{19}$ Thus, the lifestyle of the medical student may have a powerful impact which, if left unchecked, can lead to chronic health problems. $^{20}$

\section{Institutional health promotion activities}

In light of these findings, several health promotion activities have been implemented to improve the physical fitness of TCOM students. In 1987 health risk appraisal was introduced as part of a required first-year course. The "HEALTHIER PEOPLE" 21 Health Risk Appraisal Program is currently used and students complete the standard questionnaire, including measures of height, weight, body frame, TC, and HDL-C. Students participate in group interpretation and counseling sessions as part of the course. There is evidence to suggest that detection and education, such as occur in health risk appraisal, may contribute to changes in coronary heart disease risk factors in young medical students. ${ }^{22}$

Small group workshops also increase the student's awareness of health promotion. The workshops address a wide variety of health promotion topics including exercise and fitness, 
nutrition, heart disease risk assessment, stress management, and substance abuse. It is reasonable to anticipate that medical students who are conscious of their own health habits will be more likely to provide preventive medical counseling for their patients. ${ }^{23}$

At TCOM, an on-campus exercise facility has recently been introduced for student use. This facility gives students the opportunity to participate in fitness programs aimed at improving aerobic conditioning, muscle strength, and flexibility. Daily group exercise and fitness classes are also conducted. Other health promotion activities have been implemented to address problems that may extend beyond physical fitness. A major part of this effort has been the introduction of a formal student assistance program that provides professional services in the areas of marital conflict, parenting, alcohol or drug dependency, anxiety, depression, and financial matters. Plans are being developed to measure the impact of these interventions and to conduct longitudinal studies that will measure the health behaviors of medical students as they progress into residency programs and clinical practice.

\section{Conclusion}

This study of first-year osteopathic medical students indicates that their level of physical fitness is higher than that of age- and genderspecific comparison groups. Body fat percentage was found to be a strong negative predictor of fitness in both men and women. Although our methodology does not allow us to determine whether this relationship is a causal one, measures to reduce body fat in medical students seem prudent. Such reductions can be accomplished through programs that address health promotion, particularly in the areas of physical activity and diet.

\section{References}

1. Horowitz MM, Byrd JC, Gruchow HW: Attitudes of faculty members, residents, students, and community physicians toward health promotion. J Med Educ 1987;62:931-934.
2. Wyndham $\mathrm{CH}$ : The capacity for endurance exercise of thirdyear medical students. $S$ Afr Med J 1972;46:1655-1661.

3. Kay J, Howard T, Welch G: Health habits of medical students: Some perils of the profession. J Am Coll Health Assoc 1980;28:238-239.

4. Levy BS, Goldberg R, Rippe J, et al: A regular physical education program for medical students: Learning about prevention through participation. $J$ Med Educ 1984;59:596-598.

5. Wolf TM, Kissling GE: Changes in life-style characteristics, health, and mood of freshman medical students. $J$ Med Educ 1984;59:806-814

6. Grantham PR, McGraw RC, Rhodes EC: Physical fitness of first-year medical students at the University of British Columbia. J Med Educ 1987;62:923-925.

7. Parkerson GR, Eisenson HJ, Munning KA, et al: A health promotion program for medical students. $J$ Med Educ 1988;63:722-724.

8. Jackson A, Pollock M: Generalized equations for predicting body density of men. Br J Nutr 1978;40:497-504.

9. Jackson A, Pollock M, Ward A: Generalized equations for predicting body density of women. Med Sci Sports Exerc 1980;12:175-182.

10. Siri W: Body composition from fluid spaces and density, in Brozek J, Henschel A (eds): Techniques For Measuring Body Composition. Washington, DC, National Academy of Sciences, 1961.

11. Balke B, Ware R: An experimental study of physical fitness of Air Force personnel. US Armed Forces Med J 1959;10:675688.

12. American College of Sports Medicine: Guidelines for Graded Exercise Testing and Exercise Prescription, ed 2. Philadelphia, $\mathrm{Pa}$, Lea \& Febiger, 1980.

13. Cooper K: The Aerobics Way. New York, Bantam Books, 1977.

14. SAS Institute Inc: $S A S$ User's Guide: Statistics, ed 5, version 5. Cary, NC, SAS Institute, 1985.

15. Haskell W: The influence of exercise on the concentration of triglyceride and cholesterol in human plasma. Exerc Sport Sci Rev 1984;12:205-244.

16. Wolf T, Kissling G: Type A behavior and achievement of freshman medical students. $J$ Med Educ 1983;58:820-822.

17. Dishman R: Contemporary sport psychology. Exerc Sport Sci Rev 1982;10:120-159.

18. Collingwood T, Bernstein I, Hubbard D, et al: Canonical correlation analysis of clinical and psychologic data in 4,351 men and women. J Cardiac Rehabil 1983;3:706-711.

19. Mechanic D, Cleary P: Factors associated with the maintenance of positive health behavior. Prev Med 1980;9:805-814.

20. Ekelund L, Haskell W, Johnson J, et al: Physical fitness as a predictor of cardiovascular mortality in asymptomatic North American men: The Lipid Research Clinics Mortality Follow-up Study. N Engl J Med 1988;319:1379-1384.

21. Amler R, Moriarty D, Hutchins E (eds): HEALTHIER PEOPLE: The Carter Center of Emory University Health Risk Appraisal Program: Guides and Documentation. Decatur, Ga, The Carter Center of Emory University, 1989.

22. Yates B, Johnson WD, Wingo C, et al: Serum lipid changes in medical students. $J$ Am Diet Assoc 1978;72:398-403.

23. Bowles LT: Fitness programs for medical students and faculty members. J Med Educ 1987;62:945. 